\title{
DEZ ANOS DA REVISTA ELETRÔNICA DO CURSO DE DIREITO DA UFSM
}

\author{
TEN YEARS OF THE ELECTRONIC JOURNAL OF LAW HIGH SCHOOL OF \\ FEDERAL UNIVERSITY OF SANTA MARIA
}

\author{
ANGELA ARAujo da SilVEIRA ESPINDOLA \\ RAFAEL SANTOS DE OLIVEIRA \\ Editores
}

A Revista Eletrônica do Curso de Direito da UFSM completou dez (10) anos no primeiro semestre de 2016. Recentemente, em junho de 2015, a Revista recebeu a qualificação B1 na Plataforma Periódica Qualis e, até o momento, é a única revista brasileira da área jurídica com expressivo fator de impacto presente na lista "Journal Master List" da UIF.

No período de 2006 a 2016, foram 29 números publicados, 319 artigos científicos inéditos produzidos por pesquisadores nacionais e estrangeiros a Revista Eletrônica do Curso de Direito da UFSM. Esse trabalho foi possível, graças à colaboração de pareceristas, autores, editores e membros do conselho editorial comprometidos com a excelência e qualidade da produção científica. 0 grupo de pareceristas e autores, sobretudo nos últimos anos, atende rigorosamente os critérios qualitativos da CAPES. Os artigos, sempre originais, são em sua maioria fruto de pesquisas realizadas por autores ou coautores doutores, vinculados a Programas de Pós-Graduação de diferentes unidades da federação.

Toda essa produção veiculada na Revista Eletrônica do Curso de Direito da UFSM configura-se como verdadeiro diálogo entre pesquisador. Diálogo este que vêm sendo intensificado e densificado a cada novo número do periódico; e fomentado pelo trabalho sério e comprometido destes Editores e da plêiade de pareceristas oriundos de diversas IES nacionais e estrangeiras. Diálogo que tem como objetivo e alvo a socialização do conhecimento e de pesquisas científicas contemporâneas na área do "Direito".

A política editorial da Revista Eletrônica do Curso de Direito da UFSM nunca assumiu uma área temática ou linhas editoriais definidas ou pré-determinadas dentro da área do “Direito", constituindo-se, desde a sua origem, como uma pluralidade de vozes e temáticas que representam, a cada edição, as principais preocupações da pesquisa científica em direito naquele momento histórico. Sua singularidade, portanto, é retratar os temas pungentes ao 
cotidiano das pesquisas daquele ano, primando sempre pela coesão, excelência e qualidade das publicações e da gestão editorial.

E por prezar essa excelência nas pesquisas, publicações e gestão editorial, a Revista Eletrônica do Curso de Direito assume, na virada desta sua primeira década, novos desafios, a saber: (a) o aumento do fluxo da produção editorial, (b) o aumento no fator de impacto, e (c) a agilidade no tempo médio de processamento dos artigos submetidos. Desafios estes assumidos juntamente com o compromisso de manter os indicadores de qualidade já observados até então.

Em destaque, no que tange ao primeiro daqueles desafios, anuncia-se ser este o número inaugural das publicações que seguirão, a partir de agora, uma periodicidade quadrimestral, almejando-se a publicação mínima de 35 artigos científicos anuais, adotando as recomendações da coleção Scielo Brasil.

Este primeiro número de 2016, em especial, apresenta a comunidade acadêmica 20 artigos científicos originais. Dentre estes 20 artigos, 4 são de autores vinculados ao estado do RS, o que significa uma endogenia de apenas $20 \%$. Esta edição apresenta, de certa forma, uma radiografia dos principais temas tratadas em sede de pós-graduação strito sensu, eis que contempla artigos vinculados às pesquisas realizadas em Programas de Pós-Graduação em Direito em pelo menos cinco (05) estados da federação, quais sejam: PR, SP, MG, SC e ES, para além do RS. De modo geral, além destes 5 estados, no rol dos artigos há ainda que representam pesquisas realizadas em outros dois estados da federal: MT e PI. Assim: a revista contempla cinco (05) artigos de autores do PR, três (03) artigos de autores do estado de SP, dois (02) artigos de MG, um artigo de SC, um artigo do ES, um artigo do MT e um artigo do PI. O que pode ser apontado como uma boa amostragem do que está sendo pesquisado no país.

Ainda, dois destes artigos são publicações em língua estrangeira: um em inglês e outro em espanhol, são eles: (a) THE FUNDAMENTAL RIGHT TO PRIVACY IN BRAZIL AND THE INTERNET PRIVACY RIGHTS IN REGULATING PERSONAL DATA PROTECTION, de autoria de Vinícius Borges Fortes, Salete Oro Boff e Fernando Galindo Ayuda; bem como (b) DERECHOS HUMANOS, LIBERTAD Y FACTICIDAD: UNA LECTURA ALTERNATIVA DESDE EL PENSAMIENTO SARTRIANO, de autoria de Enán Arrieta Burgos.

A estes somam-se ainda os seguintes, abaixo apresentados em ordem alfabética de autor:

Alexander Rodrigues de Castro escreve sobre FUNDAMENTOS PARA UMA CRÍTICA DO ESTATUTO DO ÍNDIO: RAÇA E HISTÓRIA DE LÉVI-STRAUSS. 
André Folloni, Camila Beatriz Simm escrevem sobre DIREITO TRIBUTÁRIO, COMPLEXIDADE E ANÁLISE ECONÔMICA DO DIREITO.

Arno Dal Ri Júnior e Mariana Clara de Andrade escrevem sobre UM REGIME AUTOCONTIDO? APONTAMENTOS SOBRE O DIREITO APLICÁVEL AOS CONTENCIOSOS NO ÂMBITO DA OMC.

Bárbara Josana Costa e Marciano Buffon escrevem sobre ROBIN HOOD ÀS AVESSAS: A INDEVIDA TRIBUTAÇÃO DOS PRODUTOS DA CESTA BÁSICA.

Bárbara Michele Morais Kunde e Jorge Renato dos Reis escrevem sobre APLICATIVO SECRET: SOMOS TODOS INVISÍVEIS? UM OLHAR CONSTITUCIONAL SOBRE O DIÁLOGO ENTRE ANONIMATO E LIBERDADE DE EXPRESSÃO NO AMBIENTE VIRTUAL.

Beatriz Souza Costa e Nathalia Bastos do Vale Brito são autoras de IMPACTOS DA DECISÃO DA SUPREMA CORTE DOS ESTADOS UNIDOS NA PROTEÇÃO DO PATRIMÔNIO GENÉTICO HUMANO: CASO ASSOCIATION FOR MOLECULAR PATHOLOGY VS. MYRIAD GENETICS

Camila Maria Rosa Casari e Gilberto Giacóia escrevem sobre A VIOLAÇÃO DOS DIREITOS FUNDAMENTAIS NO SISTEMA PRISIONAL BRASILEIRO À LUZ DA TEORIA DO GARANTISMO PENAL.

Crisna Maria Muller e Dirceia Moreira escrevem sobre A EFETIVAÇÃO DOS DIREITOS HUMANOS NA CONCEPÇÃO MULTICULTURAL: CONSTRUÇÃO DA CIDADANIA COSMOPOLITA.

Dirceu Pereira Siqueira e Caroline Zanetti Paiva escrevem sobre A UTILIZAÇÃO DA MEDIAÇÃO COMO FORMA DE EFETIVAÇÃO AO ACESSO À JUSTIÇA E O PRINCÍPIO DA DIGNIDADE DA PESSOA HUMANA

Eduardo Augusto Salomão Cambi e Luna Stipp escreve sobre HERMENÊUTICA FLEXÍVEL E DISCRICIONARIEDADE JUDICIAL.

Emerson Ademir Borges de Oliveira escreve sobre RUMOS DEMOCRÁTICOS BRASILEIROS FORA DO IDEALISMO.

Guilherme Augusto Cardoso e Victor Hugo de Almeida são autores de ASSÉDIO MORAL NA ADMINISTRAÇÃO PÚBLICA: UMA VISÃO CRÍTICA DA JURISPRUDÊNCIA BRASILEIRA

Magno Federici Gomes e Carlos Frederico Saraiva de Vasconcelos escrevem sobre DAS ATRIBUIÇÕES ADMINISTRATIVAS NA GESTÃO E SUPERVISÃO DO PATRIMÔNIO GENÉTICO BRASILEIRO.

Maiquel Ângelo Dezordi Wermuth e Joice Graciela Nielsson escrevem sobre O ENSINO JURÍDICO BRASILEIRO E A FORMAÇÃO DO “MEDALHÃO” MACHADIANO: EM BUSCA DE ALTERNATIVAS À LUZ DA PROFANAÇÃO AGAMBENIANA E DA CARNAVALIZAÇÃO WARATIANA. 
ISSN 1981-3694

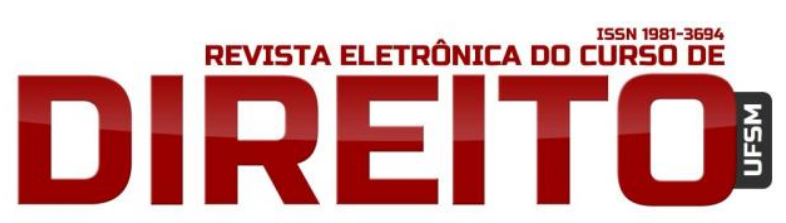

EDITORIAL

DEZ ANOS DA REVISTA ELETRÔNICA DO CURSO DE DIREITO DA UFSM

Mariele Troiano escreve ENTRE O PASSADO E O FUTURO: O PROCESSO CONSTITUINTE DE 1987-88

Paulo Rangel Ferreira e Itamar da Silva Santos Filho escrevem sobre A EDUCAÇÃO PARA O TRÂNSITO COMO FERRAMENTA DE OBEDIÊNCIA AOS PRINCÍPIOS DA EFICIÊNCIA E DA DIGNIDADE DA PESSOA HUMANA.

Thiago Fabres de Carvalho, Adriana de Oliveira Gonzaga Bisi escrevem sobre APONTAMENTOS SOBRE O USO DA FOTOGRAFIA PELA POLÍCIA POLÍTICA NO ESTADO NOVO.

E, por fim, Vanisse Monteiro Campos e Gisele Silva Lira de Resende escreve A DESESTRUTURAÇÃO FAMILIAR E O ADOLESCENTE EM CONFLITO COM A LEI: PONTOS E CONTRAPONTOS

Estes, portanto, os artigos científicos que inauguram esta edição e a nova década da Revista Eletrônica do Curso de Direito da UFSM. Nós editores, que fomos autores neófitos na primeira edição de 2006, sem vínculo institucional com a UFSM, orgulhosos de fazer parte da história e da trajetória deste periódico, registramos nosso desejo de que esta Revista se constitua, tal qual o céu da metáfora de Virginia Woolf, uma longa leitura contínua e incansável.

Boa leitura!!

Os Editores. 